\title{
Three Separated Growth Sequences of Vertically-Aligned Carbon Nanotubes on Porous Silicon: Field Emission Applications
}

\author{
Jalal Rouhi ${ }^{1}$, Hesamedin Khosravani Malayeri ${ }^{2}$, Saeid Kakooei ${ }^{3, *}$, Rouhollah Karimzadeh ${ }^{1}$, \\ Salman Alrokayan ${ }^{4}$,Haseeb Khan ${ }^{4}$, Mohamad Rusop Mahmood ${ }^{5}$ \\ ${ }^{1}$ Department of Physics, Shahid Beheshti University, Evin, Tehran 19839, Iran \\ ${ }^{2}$ Department of Mechanical Engineering, Arak Branch, Islamic Azad University, Arak, Iran \\ ${ }^{3}$ Centre for Corrosion Research, Department of Mechanical Engineering, Universiti Teknologi \\ PETRONAS, Tronoh31750, Malaysia \\ ${ }^{4}$ Research Chair for Biomedical Applications of Nanomaterials, Biochemistry Department, College of \\ Science, King Saud University (KSU), Riyadh, Saudi Arabia \\ ${ }^{5}$ Centre of Nanoscience and Nanotechnology (NANO-SciTech Centre), Institute of Science, Universiti \\ Teknologi MARA, Shah Alam, Selangor 40450, Malaysia \\ *E-mail: saeid.kakooei@utp.edu.my
}

doi: $10.20964 / 2018.10 .45$

Received: 4 May 2018 / Accepted: 25 June 2018 / Published: 1 September 2018

\begin{abstract}
Three separated growth sequences of vertically-aligned carbon nanotubes (CNTs) were successfully synthesized for the first time on porous silicon (PSi) by modifying the catalyst-nanotemplate interaction in a two-stage hot filament assisted chemical vapor deposition. The morphological differences between the aligned CNTs grown by various flow rates were investigated by means of FESEM images. The presence of single-wall CNTs (SWCNTs) was confirmed by Raman radial breathing mode peak between 100 and $400 \mathrm{~cm}^{-1}$. The low operating electrical field of the multilayer VACNTs grown on PSi is attributable to a relatively high field enhancement factor, which is the result of the geometrical configuration of the CNTs and the substrate. The findings demonstrate that multilayer CNTs have been identified as promising candidates for field emitters in numerous applications such as electron microscopy, flat panel display, as well as other advanced technologies.
\end{abstract}

Keywords: Multilayer structure; Carbon nanotubes; Two-stage hot filament assisted CVD; Field emission properties; Electrical properties

\section{$\underline{\text { FULL TEXT }}$}


(C) 2018 The Authors. Published by ESG (www.electrochemsci.org). This article is an open access article distributed under the terms and conditions of the Creative Commons Attribution license (http://creativecommons.org/licenses/by/4.0/). 